\title{
RELACIÓN MÚSICA/TEXTO \\ EN EL CANTO GREGORIANO Y EN LA POLIFONÍA Y EL CONCEPTO HUMANISTA DE RITMO MUSICAL
}

\author{
José-Vicente GonZÁlez VALlE \\ CSIC, Barcelona
}

\begin{abstract}
Following the thread of the interrelation between music and text, this study is a reflection on the humanist concept of rhythm in Gregorian Chant. The consequences of the said concept succeeded in influencing vocal polyphony, as well, which was, however, all to its advantage.
\end{abstract}

\section{Resumen}

El presente trabajo ofrece una reflexión, siguiendo el hilo conductor de la "relación música/texto", sobre el concepto humanista del ritmo en el Canto Gregoriano. Las consecuencias de dicha concepción llegaron a afectar también a la polifonía vocal, en cuyo caso, diríamos que para su bien.

Para comenzar, podríamos decir que la polifonía vocal había ido asumiendo en su propio cuerpo la esencia del Canto Gregoriano. Las primitivas notaciones de la polifonía, su ritmo fluido y "libre", su sistema tonal modal, la disposición interválica o diatonismo puramente melódico, reflejado en cada una de las partes que forman el conjunto polifónico vocal, el carácter y la estructura de los textos, los tipos de contrapunto "nota-contra-nota"(accentus) o "varias-notascontra-una"(concentus), todo parece desarrollarse en analogía con el Canto Gregoriano. Es, por lo tanto, indispensable conocer previamente esa música de todos los tiempos, si se quiere comprender bien la polifonía clásica. Los teóricos de música hablan también de estas analogías, al expresarse, con frecuencia, del modo siguiente "Assi como en Canto de Organo ay [...], assí también las ay en Cantollano:"1.

Sabemos que los humanistas se interesaron especialmente por el ritmo por el Canto Gregoriano. En este sentido, se encontraron con el panorama siguiente: mientras que la polifonía vocal había desarrollado en su notación un sistema rítmico completo, observaban que, en el canto

1. Pedro Cerone, El melopeo, Nápoles 1613, p. 451. 
gregoriano, el ritmo pertenecía más a la práctica musical, es decir, a la oralidad, que a la teoría de la notación. Por otro lado, veían que, a su modo de entender, el acento gramatical de los textos latinos era continuamente maltratado por la música. Al intentar remediar la situación, la oralidad que acompañaba al Canto Gregoriano empezó a sentirse, una vez más, amenazada, e, incluso, con riesgo de quedar interrumpida. Examinemos algunos aspectos de este interesante proceso.

En el Canto Gregoriano existe una relación íntima, que podríamos denominar genética, entre música y texto, ya que la música nace directamente del texto latino sacro. El texto del Canto Gregoriano, por otra parte, está redactado en prosa vulgar latina. Su música se ha transmitido en neumas cursivos, al principio, y, más o menos desde el siglo XIII, en notación cuadrada. La notación neumática gregoriana y su realidad sonora no están relacionadas entre sí de una manera exacta, fija o exclusiva, de modo que la imagen gráfica musical exija una única realidad sonora. Una relación música/realidad-sonora, como a la que estamos acostumbrados por la notación de la música occidental, iría desarrollándose, poco a poco, en los neumas, al transformarse éstos en escritura libraria, para, desde ahí, llegar a convertirse en nuestra notación musical occidental. Los códices neumáticos gregorianos, al no desarrollar su notación en sentido rítmico, tuvieron que ir siempre acompañados de una oralidad, que, en cierto modo, llegaría hasta nosotros. Mientras la música mantenía su carácter monódico, es lógico suponer, que el ritmo se transmitiera oralmente. La primitiva notación neumática, fundada en una mezcla de puntos o acentos y signos quironímicos, presuponía el conocimiento de las melodías y de su ritmo y, por lo tanto, la existencia de una práctica de transmisión oral. La quironimia, mucho más que una escritura propiamente dicha, era un "danzar de la mano" junto a las melodías, es decir, mucho más un arte propio, que una ayuda a la memoria. Ahora bien, el rol de apoyo a la memoria estuvo unido a la notación musical, hasta que ésta llegó a ser abarcada profundamente por la teoría, es decir, hasta el nacimiento de la actual notación.

Los neumas, al referirse a textos sacros latino-vulgares en prosa, tenían como cometido, de un modo semejante a los signos prosódicos gramaticales, ayudar a pronunciar musicalmente bien los textos. El contenido musical de los neumas no era, por lo tanto, autónomo; la música no existía de un modo independiente, sino que estaba esencialmente relacionada con el texto.

Respecto a la interpretación rítmica de los neumas gregorianos, la tesis generalizada de Solesmes, de que todas las notas poseen igual duración no está científicamente justificada, según E. Jammers ${ }^{2}$, por falta de continuidad histórica. Existen, en la teoría musical, algunas alusiones al ritmo, aunque pocas y brevísimas. Pero, antes de entrar en el tema del ritmo, sería necesario recordar algunos datos históricos de interés. Si la antigüedad clásica latina (s. II a. d. C. al s. IV d. d. C), es decir, la época inmediata anterior al coral gregoriano, medía las palabras según la duración natural de las sílabas, no según los acentos, el Canto Gregoriano crece y se desarrolla en la denominada época postclásica, que comienza a finales del siglo IV. Entonces dominaba ya el latín vulgar, cuyo ritmo empezaba a fundarse en el acento silábico, dejando de establecer diferencias entre sílabas largas y breves ${ }^{3}$. Por otra parte, la notación neumática gregoriana, al princi-

2. Ewald Jammers, Tafeln zur Neumenschrift, Tutzing 1965, p. 33.

3. Dom Paolo Ferretti, Esthetique Grégorienne, vol. I, Solesmes 1938, p. 6 ss. 
pio, tampoco podía incluir diferencias entre tiempos largos y breves, no sólo porque al quironomista (director) le sería imposible indicar, a la vez, dos signos diferentes, sino también porque, durante el desarrollo de la quironimia gregoriana, imperaba el recitativo, es decir, la prosa, con sílabas aproximadamente iguales, aunque con o sin acento tónico. Si ciertamente no puede existir una música sin un ritmo, éste pudo ser el resultado secundario del arte de la quironimia, es decir, del modo de interpretar las notas o neumas correctamente, repartiéndolos entre las sílabas, de acuerdo con el acento silábico, el oratorio y el sentido de los textos que se recitaban. Los posteriores "modos" rítmicos medievales, creados para la música polifónica, determinaron el ritmo por medio de las artificiales proporciones de las sílabas, según la métrica del latín clásico. La nota, entendida como duración propia, no se conocía entonces, sólo existe desde el Ars Antiqua. Por otra parte, sin un sistema rítmico preciso, aplicado a la notación musical, hubiera sido impensable el desarrollo de la polifonía vocal.

Explorar el ritmo del canto gregoriano es, por lo tanto, un trabajo de investigación, al que la notación neumática sólo puede ayudar de un modo incompleto, es decir, en tanto que los neumas se corresponden con sílabas. El ritmo gregoriano, a tenor de la escasa, por no decir casi nula, información de la teoría musical, perteneció más a la tradición oral, que a la escrita, durante la Edad Media. Esa oralidad, sin embargo, se sintió amenazada, por no decir, interrumpida por los humanistas. Ésto fue debido, a que el pensamiento básico humanista se fundaba: 1) en la absoluta desconfianza, como principio, de toda tradición de procedencia posterior a la antigüiedad y 2) en la imagen ideal de perfección artística de la antigüedad. Dentro del mundo ideal de la antigüedad, los humanistas incluyeron también la época de la primitiva iglesia cristiana, es decir, la de los Santos Padres. En aquella época, según Erasmo, estaba unida la religiosidad cristiana con la más fina formación; había, por lo tanto, que recuperar aquella unión, que la posterior incultura destruyó. Desde este punto de vista crítico, los humanistas dirigen la mirada al Canto Gregoriano, a su repertorio, su teoría y su interpretación.

Mientras que toda la teoría musical medieval, desde Aureliano de Reomé (s. IX), se ocupa ampliamente de aspectos relacionados con el sistema musical gregoriano, se muestra, sin embargo, muy silenciosa respecto al ritmo. Klaus Wolfgang Niemöller ${ }^{4}$ dice, en este sentido, que "mientras la teoría de la solmisación, como ayuda para el aprendizaje de las melodías gregorianas no falta en ningún tratado, la cuestión sobre el modo de interpretar el canto gregoriano, tal como nos encontramos con frecuencia en las normas, estatutos y decretos eclesiásticos, es recogida por la teoría musical sólo esporádicamente a modo de apéndices. Aún así, se conocen pocos tratados que se ocupen del ritmo gregoriano. Uno de ellos, bastante olvidado y, sin embargo, muy importante respecto al ritmo del Canto Gregoriano es el «Quatuor principalia musices», atribuido por Coussemaker a Simon Tunstede." Aunque esta atribución ha sido cuestionada últimamente $^{6}$, no obstante, el tratado debió ser redactado hacia el año 1380.

4. Klaus Wolfgang Niemöller, Die Theorie des gregorianischen Gesanges im Mittelalter, en Geschichte der Katholischen Kirchenmusik, vol. I, Basel 1972, p. 331.

5. E. Coussemaker, Scriptorum de Musica Medii Aevi, Tomus IV. p. 200-298.

6. Cfr. G. Reaney, Musica Disciplina VIII, p. 73. 
El capítulo LVIII $^{7}$ del apartado denominado Tertium principale del citado tratado se ocupa de la interpretación del canto llano y lleva el título siguiente: "Quod tria necessaria planum cantum modulandi. Et de modo pausandi et pronuntiandi planum cantum." Aquí se afirma que el Canto Gregoriano ha de interpretarse dando a todas las notas el mismo valor, si bien, respecto al canto melismático, se habla de ciertos matices interpretativos, que, indirectamente, afectan al ritmo:

"Circa planam musicam adhuc insistendum esse mihi videtur, ut ars eam canendi tamen a multis incognita hic elucidetur. Nam cantus planus modulari debet aequaliter, in modo, et in mensura." [....] "Hiis igitur consideratis, sciendum est quod omnis planus cantus pronuntiari debet in quinto modo aut in sexto, id est, per longas aut per breves, quia in plano cantu omnes notae sive voces naturaliter aequales. Sed causa melodiae et coloris, unius vocis aliqua pars auferenda est et alteri concedenda, ut in sequentibus patet. [...] Quia secundum naturam plani cantus omnes notae sunt aequales."

A los humanistas les resultaba extraño y molesto ese ecualismo interpretativo del canto gregoriano, pues iba contra su modo de pensar. Para ellos la música, ante todo, sólo podía desarrollar su efecto subordinándose a las leyes del idioma. Pensaban, que así sucedió realmente en la antigüedad, incluida la época de la antigua iglesia. A través de reflexiones de este tipo, Erasmo y Glareano dan a entender, que la falta de respeto en diferenciar las sílabas largas y las breves en el canto coral -incluido el melismático- es algo improcedente, que se introdujo posteriormente por incultura. Así opinan también Andrés Ornitoparchus (Musicae activae micrologus, 1517) y Blas Rosetti (Libellus de rudimentis musices, 1529). Ambos distinguen en el canto gregoriano dos campos, en primer lugar, el que se funda en los principios de la gramática (accentus), a la que hay que respetar como la ley más suprema, con el fin de declamar bien los textos y, otro, que, por ofrecer un desarrollo musical más rico, libera a la música de su estrecha unión con el texto (concentus).

Sobre el canto de los himnos gregorianos, en cambio, todos los teóricos coinciden en afirmar, que, aunque la notación musical no lo exprese, se trata siempre de música mensural. De nuevo, nos enfrentamos aquí al problema de la oralidad. Sabemos que, en la alta Edad Media, se comenzó a componer himnos latinos haciendo coincidir el acento tónico de la palabra con una sílaba larga por naturaleza, para, desde ahí, llegar, en un momento determinado, a interpretar el acento silábico en sentido métrico-cuantitativo, es decir, como una duración más larga. Así se abrió paso, poco a poco, la interpretación cuantitativa del acento silábico. Existen himnos medievales, escritos aparentemente en dímetros trocaicos (Larga-Breve Larga-Breve Larga-Breve Larga-Breve), cuando en realidad su ritmo se basa en el orden de acentos (Acento-Atona Acento-Atona Acento-Atona Acento-Atona: Stá-bat má-ter dó-lo-ró-sa). Las nuevas lenguas románicas fundaron ya el ritmo de sus versos, no en la cuantidad de las sílabas, sino en el orden de acentos intensivos. Según fueron desarrollándose las lenguas vernáculas y generalizándose su uso, el

7. Ed. Coussemaker ibd. p. 251 col. a. 
latín vulgar pasó a convertirse en un lenguaje académico-escolástico, donde el orden prosódico jugaría un rol análogo al que había desempeñado anteriormente el orden métrico. Es decir, las sílabas acentuadas empezaron a ser interpretadas como largas. Así fue apareciendo una manera rítmica, retórico-académica, de recitación del latín medieval. El tratado de Salinas ${ }^{8}$ podría considerarse como un intento humanista más de interpretar el orden de acentos, como si se tratara de un sistema métrico cuantitativo, es decir, equiparando las sílabas acentuadas a las largas y las átonas a las breves, como puede observarse en el siguiente ejemplo:

P. Salinas, ed. I. Fernández de la Cuesta, p. 635-636

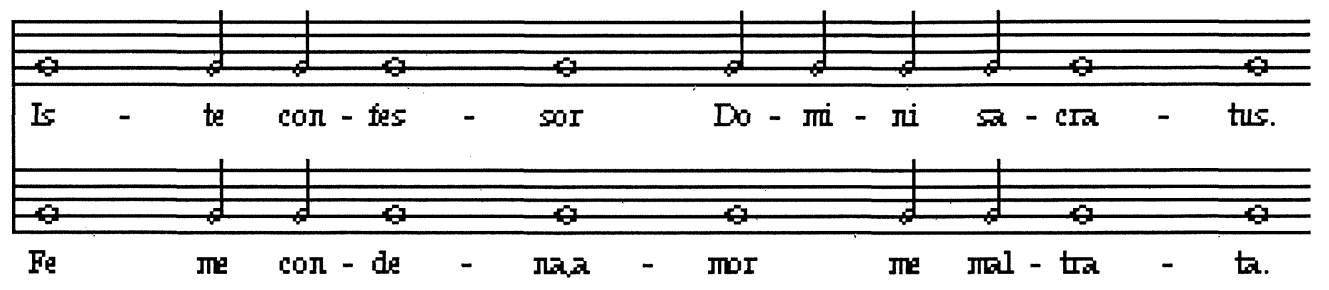

La interpretación del canto gregoriano, determinada por la gramática, intentó imponerse de un modo general, en el siglo XVI, para el canto de las lecturas y de las melodías silábicas y melismáticas. Desde el campo de la interpretación, el ritmo, fundado en el acento gramatical, se introdujo en la notación. Es frecuente encontrar en los impresos gregorianos del siglo XVI palabras como Dómini, glória etc, en notación silábica, escritas del modo siguiente: Longa-BreveBreve-Longa-Breve-Breve (Glareano, Dodekachordon II, 17 y 18). Prácticas de este tipo son desarrolladas por el discípulo de Palestrina, Giovanni Domenico Guidetti, a partir de 1580, y formuladas en un sistema convencional de notación rítmica para el canto gregoriano. En conexión con este sistema, se crea, a finales del siglo XVI, una notación especial "alla Romana", que difiere de la tradicional.

La aplicación del concepto humanista, métrico-cuantitativo, del acento tónico del lenguaje no se limita al Canto Gregoriano, puesto que la polifonía vocal del siglo XVI se siente también íntimamente afectada. Un examen atento de las composiciones musicales, prueba que los músicos de esa época sentían fuertemente el carácter rítmico-cuantitativo del acento tónico, haciéndolo coincidir con una nota larga. Paolo Ferretti afirma que "Il semble bien que, ceteris paribus, on puisse appliquer même à la composition polyphonique la loi gregorienne". ${ }^{9} \mathrm{P}$. Cerone, ${ }^{10}$ al tratar de la aplicación del texto a la música polifónica, indica que se ha de proceder "a imitación del Canto Llano". Toda música, hasta el 1600, no conoce otro ritmo que el cuantitativo, es decir, el fundado en la diferencia entre notas largas y cortas. Hay que esperar al siglo XVII,

8. Pedro Salinas, De Musica Libri Septem, Salamanca 1577 y edición traducida al castellano, Ismael Fernández de la Cuesta, Francisco Salinas, Siete Libros sobre la Música, Madrid 1983.

9. Paolo Ferretti, Esthétique Gregorienne, vol. I, Abbaye Saint-Pierre de Solesmes 1938, p. 40.

10. Pedro Cerone, op. cit., Nápoles 1613, p. 513. 
para que empiece a desarrollarse un ritmo intensivo musical, absolutamente nuevo, fundado en el acento de la armonía o del compás y no solo en la duración de las notas.

Los teóricos españoles de los siglos XVI y XVII son tan poco explícitos sobre el ritmo del Canto Gregoriano, como los del resto de países de nuestro entorno cultural. Juan Bermudo, en el siglo XVI y Andrés Lorente en el siglo XVII, al tratar del "canto llano", no se ocupan del ritmo, si no es para recordar que, aunque en él existen diversidad de figuras, todas, sin embargo, poseen el mismo valor. Veamos lo que escribe Bermudo:

"La tercera señal es los puntos: los quales inventa- / ron para subir y abaxar en el canto. Aunque con / diuersas figuras en canto llano sean señalados: / todos tienen un mesmo valor, excepto el que tiene / dos plicas que vale dos compases. Plica llamo / un rasgo que desciende del punto. Vnas vezes esta / la plica a la mano derecha, y otras a la izquierda / del punto: pero siempre descendiente en canto lla- / no." 11

Cerone de Bérgamo ${ }^{12}$ es, excepcionalmente, el teórico que se ocupa más detenidamente del ritmo del cantollano. Sus afirmaciones intentan conciliar, en cierto modo, el concepto humanista de la época anterior con la práctica tradicional. Su exposición se sitúa en línea con el tratado, anteriormente citado, de Tunstede. Cerone comienza definiendo que el canto llano es "una simple e ygual pronuncia de figuras", para pasar después a exponer una teoría rítmica del canto gregoriano:

p. 377 “[...] el Cantollano es vna simple / e ygual pronuncia de figuras: las quales no / se pueden aumentar ni disminuir: y que por / esta causa se llama Cantollano, Cantofirme y Canto immensurable. / Aunque lo dicho es verdad, con todo esto daremos aqui differente valor à las sobre- / dichas notas: no como si realmente fueran en Canto de Organo [...] / [...] si no / fingidamente sirviendonos del juyzio"

p. 378 “Adviertan pues primeramente, que esta nota triangulada pronunciamos / mas apressuradamente que ninguna de las otras, como si le dieramos en Canto / de Organo el valor de medio compas y sirve para el tiempo que se ha de / dar à la sylaba breue. Esta quadrada y sin plica entonaremos mas larga, y al doblado / de la passada; dandole el valor de vn compas : la qual seruira para el valor de las / notas ò sylabas ordinarias, que caminan por las cuerdas del tono. Mas a esta otra / quadrada y con plica, le daremos como el valor de vn compas y medio, y seruira pa- / ra la sylaba precedente à la sylaba breve, a do quiera que sea. Iten para la terminacion / del semipunto : y para la baxada del punto entero, y para su penultima sylaba. / A esta otra nota doblada y sin plica, entonaremos mas larga, atribuyendole co- / mo el valor de dos compases, pero dividiendolos casi en dos partes con la vocal / de la sylaba que tuviere escrita de baxo , y de modo como si la vocal (que es vna) / fuera escrita duplicadamente, como Doominus pro Dominus; peerfrui pro perfrui, etc. / pero hase de hazer con mucha gracia, y de manera que no desdiga, sonando mal al / oydo. Finalmente con esta manera de nota entonamos la sylaba con voz

11. Juan Bermudo, Declaracion de instrumentos musicales, Ossuna, 1555, fol XXIr.

12. Pedro Cerone, op. cit., "De la Musica del Cerone / Que es de los Auisos necess. en Cantollano." 
RELACIÓN MÚSICA/TEXTO EN EL CANTO GREGORIANO Y EN LA POLIFONÍA Y EL CONCEPTO HUMANISTA DE RITMO MUSICAL

mas / llena y mas sonora, tiniendola mas larga de las otras, como si fuera del valor de / dos compases enteros."

p. 412 "Assi como para saber escriuir es menester saber leer muy bien, assi para saber / cantar con buena y perfeta orden la letra, es menester cantar bien la sol fa : / y no se puede cantar totalmente bien, si no se sabe lo que se ha de detener / en algunos puntos, y apresurarse en otros ; y para esto segun algunos ay nue- / ve differencias de puntos en figura, y son estos: Punto alphado, punto ligado, punto / de ligadura, punto doblado, breue, semibreue, semibreue alphado y semibreue atado. / los quales en sustancia son solamente tres differencias; es à saber, Alphados , / Quadrados, y Triangulares. "[...]

Cerone distingue dos maneras de interpretación rítmica del canto gregoriano: una moderna -implantada por los humanistas-, que podríamos denominar "mensuralista", que ordena diferenciar entre valores breves y largos y, otra, antigua o "ecualista", que consiste en dar a todas las notas un idéntico valor:

p. 412 "Quien vsare destas y otras differencias de valores, hara segun algunos modernos; I y quien cantare todos los puntos indiferentemente (hablo en lo que es Cantollano / comun) con la misma medida y valor, y con ygual tiempo, guardara la orden de los antiguos : y confirmara ser verdad, que el Cantollano es canto firme, vniforme, e in- / mensurabil ; como queda dicho en el Cap. 7 de las Curiosidades : y que es vna simple e ygual pronunciacion de figuras, las quales (segun S. Bernardo) ni se pueden aumen- / tar , ni disminuyr."

Respecto al compás del cantollano, Cerone diferencia tres maneras, una, según la gramática, es decir, que establece diferencias entre "sílabas breves y largas" y se usa para la salmodia, otra "de proporción ternaria", es decir, propiamente mensural, para los himnos y, una tercera que da a todas las notas el mismo valor, es decir, ecualista, para el resto de las melodías. Respecto al compás del Cantollano, declara que "aunque se nombren los compases" no hay que entenderlos como los de canto de órgano":

p. 414 “[...] diremos algo cerca del Compas vsado en Cantollano; el qual / canto presupuesto sea llano e inmensurable (respecto al Canto de Organo) con todo / esso en vna cierta manera, es mensurable, siendo que en todas las cosas se requiere / guardar el Compas. Tres Compases ay en Cantollano, vno sirue para la Salmo- / dia, otro para los Hymnos , y el tercero para todo lo demas puntado. El Compas de / los Salmos no mira hazer todos los puntos yguales si no va midiendo todas las syla- / bas breues y longas segun las reglas Gramaticales : de forma que tanto tiempo gasta / en vna longa, como en dos breues, poco mas ò menos. El que en la Salmodia huuier- / re de lleuar el Compas, no solamente à de ser buen Cantor, si no tambien buen latiI no : entiendo esto de Compas ygual, y los puntos desiguales. Vna vez entran en un Com- / pas dos puntos, otra vez tres. En todo y por todo en la Salmodia se deue guardar el / acento especialmente en la demediacion de los Versos, y en las Sequencias. Esten / muy auisados en esto los principiantes, porque algunos descuydandose, hazen grandes / yerros, quebrando los acentos, sin proposito ninguno. 
El compas de los Hymnos, en algunos es desigual, es à sauer à Proporcion ternaria , / adonde (por dezir assi) entran tres Semibreues en vn Compas : aunque en muy pocas / partes estan bien apuntados tales Hymnos. Esto digo, porque casi todos los pun- / tos tienen quadrados; aunque la palabra, el oydo, el uso, y la pratica costriñen al Can- / tante cantarlos segun se deue, y conforme su composicion." [...] "El Compas verdadero del Cantollano, es entero , / indiuisible y siempre vno: y assi no tiene mas que vna parte, que es el herir de vn golpe / (sin parar digo en la parte alta ò baxa) y luego leuantar : como quie sacude vna ropa / con vna varra, que tiene si no el baxar de la mano; y todos los puntos son yguales, digo / que tanto tiempo se pierde en cantar vn punto quadrado con dos plicas, como otro con vna; como el punto alphado ò como el triangulado :

Al haber sido impresos algunos cantorales de canto gregoriano con notación mesural, se ha pensado que esto podría ser una prueba evidente en favor del mensuralismo. Cerone, en el párrafo que sigue, dice, sin embargo, que tales figuras fueron tomadas prestadas del canto de órgano por los cantollanistas, aunque los cantos, en los que tales figuras mensurales aparecen, no pueden ser denominados "con razón" cantollano:

p. 415 [...]"avnque (como dicho es, y somos pa- / ra dezir) por ser las figuras differentes, $v$ san algunos hazer alguna poca differencia, dando / mas tiempo a vn punto que à otro, y menos à vno que à otro: pareciendoles que las tan- / tas variedades no han sido formadas en balde; no aduertiendo estos Señores, que los / Cantollanistas las tomaron prestadas del Canto de Organo, solo para comodidad de sus / canturias, como dixe en fin del Cap. 64. de las Curiosidades à planas 298. Aduiertan / finalmente que los dichos Hymnos y Credos, no se pueden llamar con razon Cantollano, si no de Organo : iten aduiertan que en Cantollano, aunque se nombren los Com- I pases, no se entienden como en Canto de organo : porque alli se rigen por Modo , / Tiempo y Prolacion , y aca no ay nada desto."

Los puntos sueltos, que llevan a la derecha una plica, sirven para indicar el acento silábico:

p. 415 "Para cantar bien la letra ha de aduertir el nueuo y discreto discipulo, que en cada I punto quadrado que no estuuiere atado, (ecetuando pero algunas vezes en los / Hymnos y Credos, digo quando van cantados con Compas binario ò ternario, que / entonces (como dicho es mas vezes) no es Cantollano, si no de Organo) se ha de po- / ner vna sylaba: deteniendose algo mas en el punto que tuuiese plica; y casi el doblado / en el de dos plicas. Donde tambien es necessario mirar los puntos en que se hazen / y alargan los accentos de la letra : auisando desta mane$r a, q u e$ los puntos sueltos que / tuuieren a la mano derecha una virgula (esto es una raya ò plica) siruen para detener / en ellos el accento $: y$ los otros puntos que no tuuieren virgula, son para las otras syla- / bas donde no se haze accento."

A continuación, apoyándose en el célebre tratado de B. Rosseti, Cerone insiste en el modo ecualista de interpretación rítmica de los cantos neumáticos, en los que tampoco han de guardarse diferencias de valor, fundadas en el acento gramatical. Lo que justifica, al afirmar, más adelante, que la música es tan arte liberal, como la gramática y, por lo tanto, debe obedecer sus propias leyes: 
RELACIÓN MÚSICA/TEXTO EN EL CANTO GREGORIANO Y EN LA POLIFONÍA Y EL CONCEPTO HUMANISTA DE RITMO MUSICAL

p. 420 "Aduiertan bien à esta parabola y veran que consona con lo que dize Blas Roseto en / su obra, intitulada Libellum de rudimentis Musices : adonde reprehende à los que cantan- / do, siendo sylaba breue, la pronuncian por luenga : y quiere que vna semejante dis- / cordancia ò licencia, se vse solamente en los cantos que tienen ligaduras, neumas, y es-pecies de coniunciones, como lo en los Introytos, Graduales, Responsorios, etc. / Y esto en tales casos se concede ; por quanto: Debemus implere omnes colores Musicae : et hic /(segun dize) Gramatica ancilla est Musicae, sicut affirmaverunt vates sapientissimi : / (y sigue diziendo) Architas namque et Aristoxenus . subiectam Musicae Gramaticen Dixerunt. Y en verdad, buenas me parecen estas opiniones; porque si bien considera- / mos, es cosa muy dura de sufrir, quando vno no es señor en su casa a lo menos; y que de otros haya de ser echado della contra razon, y sin justicia. Si la Musica (como sa- / bemos) es Ciencia y Arte liberal tanto como la Gramatica, porque no ha de tener / sus derechos cumplidamente? porque ha de derogar sus leyes y ordenes por mante- / ner à las de la Gramatica? Esta pues determinado que lo vno y lo otro se haga de mo- / do , que cadauno de los subditos obedezcan a su Rey; es à sauer que los Gramaticos, Poetas y Oradores sufran lo que manda y ordena el Canto se guarde en sus Pronuncias, que es en los Introytos, Alleluias, Offertorios , Graduales, Comuniones y en to- / do lo demas que se canta por punto ; avnque sea cosa contra las leyes de su Señor". Según la parábola: "El Sonido, rey de la Harmonia Ecclesiastica, engendró dos hijos: la Gramática y la Música, es decir, el acento y el canto."

Para calmar las aspiraciones humanistas de acentuar bien las palabras, Cerone, en la página 421 de su tratado, presenta una serie de soluciones, como las que siguen, indicando, en el pentagrama de arriba, cómo está escrito el canto y, en el de abajo, el modo de interpretarlo:
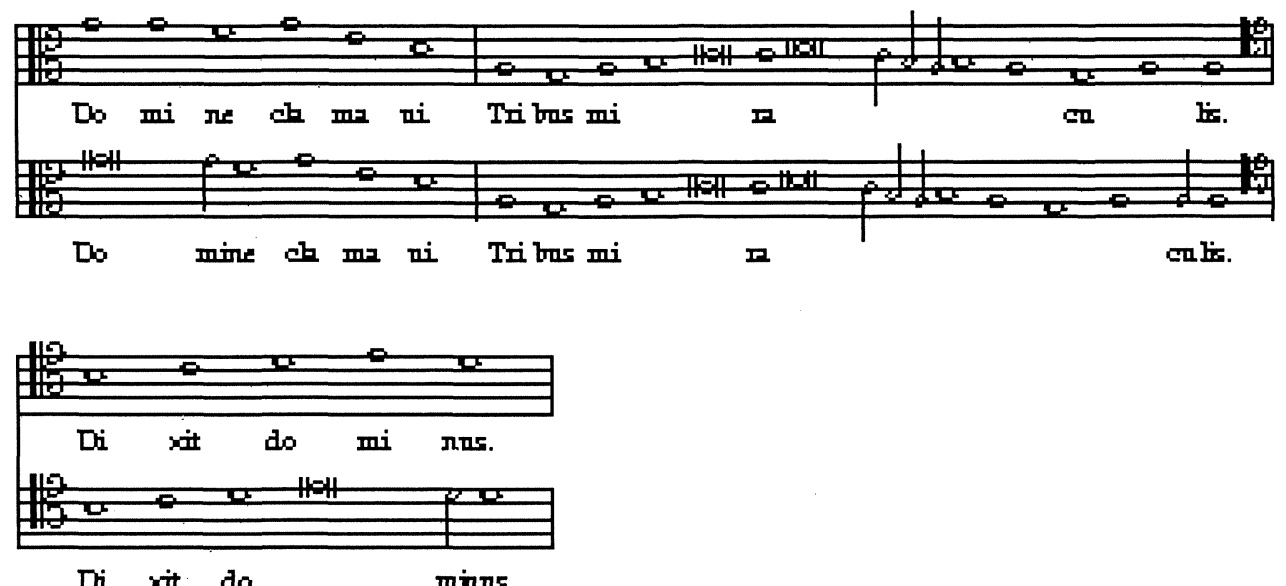

Cerone concluye este apartado citando a San Agustín y defendiendo sin ambigüedad la postura tradicional de interpretar el Canto Gregoriano, es decir, la denominada práctica de los antiguos, que no obedece tan al pie de la letra las leyes de la gramática:

p. 422. "Esto pongo assi para satisfacer à los muy persumados, y no porque haya razon que lo / pida : que sea verdad tenemos por testimonio à Sant Augustino que fue intelligente de / Musica y Gramatica; el qual en el 3. lib. de su Musica, tracta de las sylabas, verso / y metro ; hazien- 
do differencia entre verso y prosa, mas no hallaran que diga en / tales cantos se hagan las sylabas, del modo que ellos dizen y quieren; que como Can- / tollano ha de valer lo que vale , y no ha de dar lugar siempre à la Gramatica, si no en / las ocasiones que arriba se dixeron."

p. 451 "Las rayas ò virgulas que atraviessan todas las reglas (quatro ò cinco que sean) son / para muchas cosas : como es para la solennidad del canto ; para hazer alli diffe- / rencia de las reglas comunes y generales; siruen tambien para guardar las presas de los / Responsos, y para las Clausulas de los Tonos, que alli se ponen por señal ; tambien pa- / ra tomar descanso y aliento , como las Pausas de Canto de Organo. Esto es enquan- / to à las Pausas grandes; que las pequeñas, no siruen mas de apartar las ligaduras y pun- / tos atados : diziendo Gafforo en el 8. del prim. de su Prat. Describunt notatores in / Antiphonis et nocturnis Responsorijs atque Gradualibus neumam certa linea in modum / pausae cantilenas terminantis omnia linearum intervalla complectente : dividentem, / distinctiones : qua quidem innuunt vocis ipsis respirationem. Y sigue diziendo : / Neque respirandum 'est ante ultimam cuiusuis dictionis sylabam, nisi complures fue/ rint notulae soli syllabe suppositae : tunc enim necessitate urgente, poterit Cantor post non / ultimam dictionis syllabam, respirare, etc." 